\title{
Is Current Trade Pattern Between the Developed and Developing Countries Environmentally Sustainable?
}

\author{
Sang Won Yoon ${ }^{1}$ \\ ${ }^{1}$ Department of Economics and Finance, Southern Connecticut State University, New Haven, U.S.A. \\ Correspondence: Sang Won Yoon, School of Business 232, Southern Connecticut State University, New Haven, \\ CT, 06515, U.S.A. Tel: 1-203-392-5254. E-mail: yoons1 @ southernct.edu
}

Received: February 22, 2016

Accepted: March 25, 2016

Online Published: April 25, 2016

doi:10.5539/ijef.v8n5p138

URL: http://dx.doi.org/10.5539/ijef.v8n5p138

\begin{abstract}
This study examines global environmental sustainability in an open economy with international trade by studying the pattern of trade between the developed country and the developing country. Assuming that both economies are productive enough to grow and regulate pollution emissions optimally over time via emission tax, it is found that the developing country is bound to specialize in producing the pollution-intensive goods in a growing economy as long as there exists a sufficiently great technology gap in the production of environmentally friendly goods between the developed country and the developing country. The conclusion holds even if the marginal valuation of environmental improvement increases rapidly in the developing country. The developing country needs to export pollution-intensive goods where it has a comparative advantage in producing to finance imports of environmentally friendly goods that it values more over time. It is suggested that global cooperation for technological development to reduce pollution in the dirty manufacturing industry is needed to prevent ever-worsening environmental degradation in developing countries.
\end{abstract}

Keywords: sustainable economic growth, open economy, international trade, technology gap

\section{Introduction}

Environmental sustainability in the global economy with international trade has received great attention in the recent literature (Greenstone \& Jack, 2015). The emerging pattern of international trade between the developed country and developing country since the 1990s has produced massive pollution in the developing countries such as China and India, and has raised serious research concerns. Causal observations reveal that the developed countries have gradually moved toward the promotion of service industries and shifted away from resource- and pollution-intensive manufacturing industries such as steel and chemicals. The share of the manufacturing industry as a percentage of gross domestic product has experienced continuous declines for a number of high-income countries, including the United States, the United Kingdom, France, Japan, and Germany, from 1990 to 2014 (Figure 1).

On the other hands, the consumers in the developed countries have increased their consumption of imported physical goods that are resource and pollution intensive (Figure 2) (i.e., Ahmad \& Wyckoff, 2003; Helm et al., 2007; Druckman et al., 2008; Lopez \& Yoon, 2014a). The developing countries that specialize in the production of pollution-intensive manufacturing goods have in turn increased imports of clean goods such as services and high-tech green goods from developed countries. Figure 3 illustrates that Brazil, Russia, China and India (BRICs) have been importing an ever-increasing volume of services that are relatively cleaner than are manufactured goods (Note 1). Due to such a continuous shift of production of pollution- and resource-intensive manufactured goods from developed countries to developing countries, the air pollution level in the developing country has increased over time and remains stably high (Note 2). 


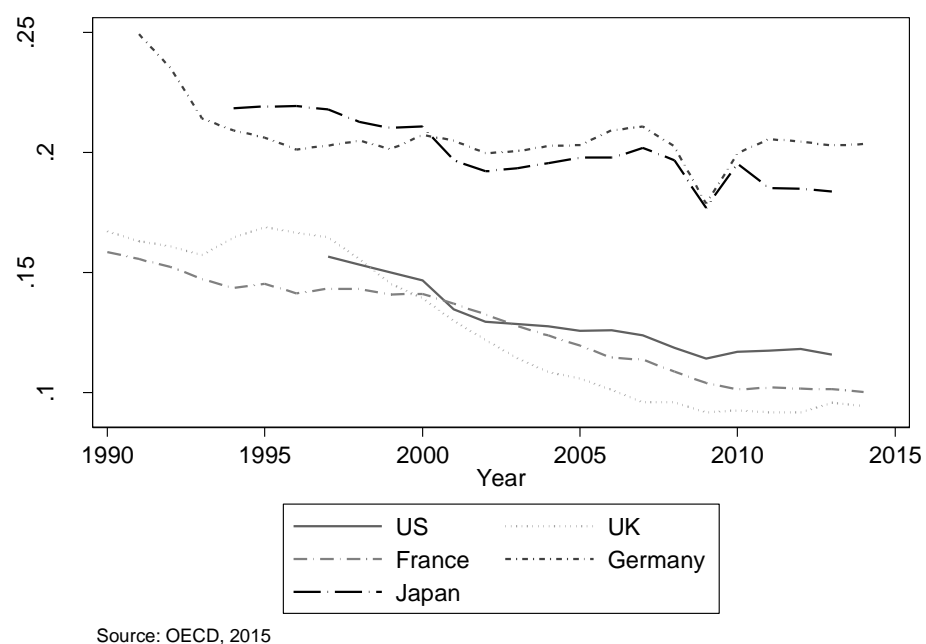

Figure 1. Production of manufacturing products (share of GDP) from 1990-2014

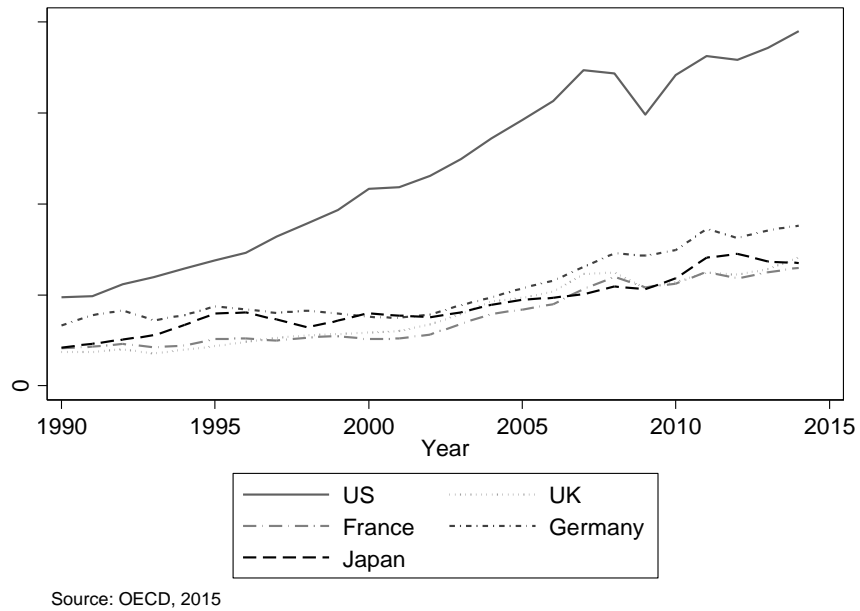

Figure 2. Imports of manufactured goods for household consumption from 1990-2014

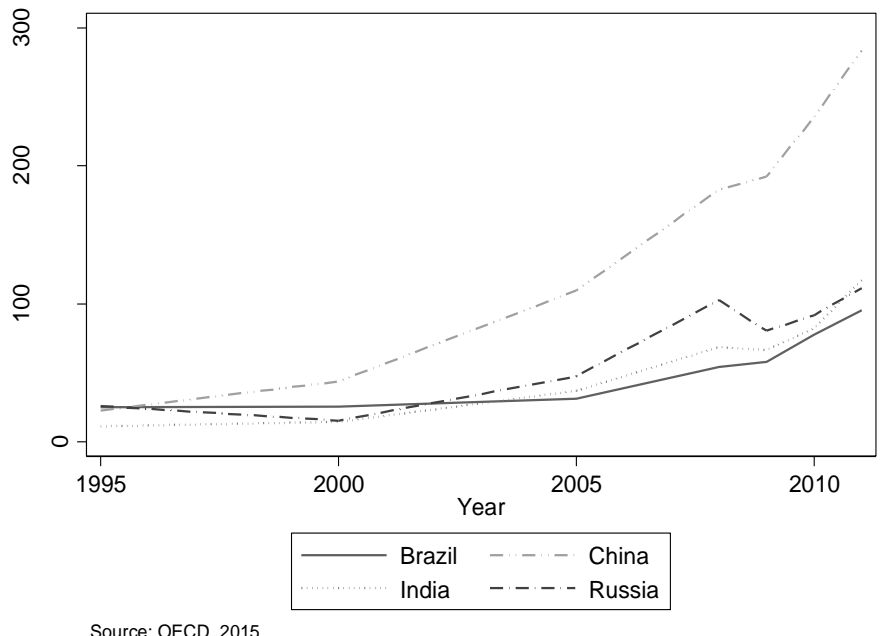

Figure 3. Imports of services from OECD countries to BRICs from 1995-2011 
One of the commonly used indicators describing the level of air pollution is particular matters (PM). PM refers to the mass concentration of particles with a diameter of less than $10 \mu \mathrm{m}$ (PM10) and particles with a diameter of less than 2.5 $\mu \mathrm{m}$ (PM2.5) (Note 3). The PM2.5 is known to cause more serious health problems than PM10 because they can get deeper into human lungs, and some may even get into the bloodstream (Note 4). Except for Russia, PM2.5 for BRICs have been increasing recently, and the population exposed to levels exceeding the WHO guideline value of PM2.5 air pollution remained at an all-time high (i.e., more than 50\% of the domestic population) since 1990, as can be seen in Figures 4 and 5, respectively.

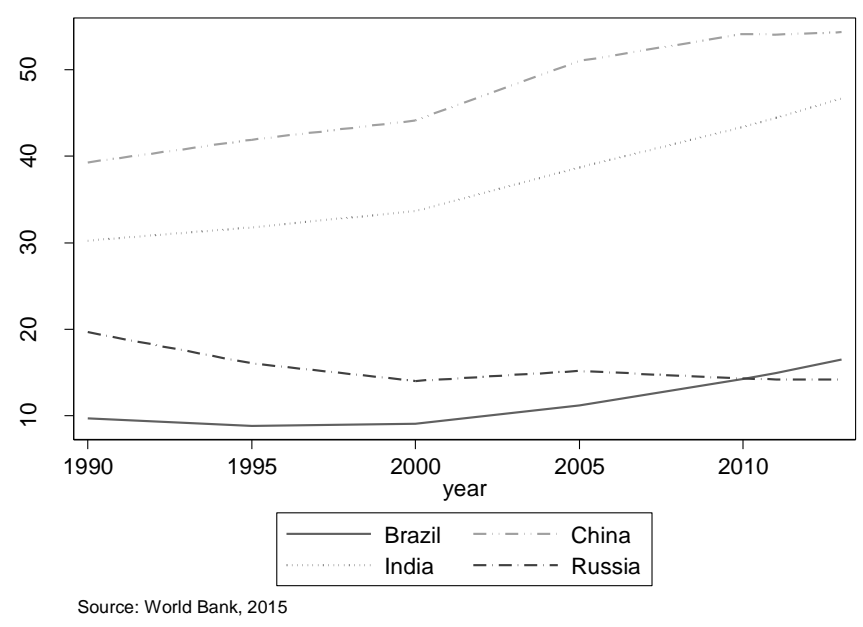

Figure 4. Annual mean PM 2.5 (micrograms per cubic meter) for BRICs from 1995 - 2013

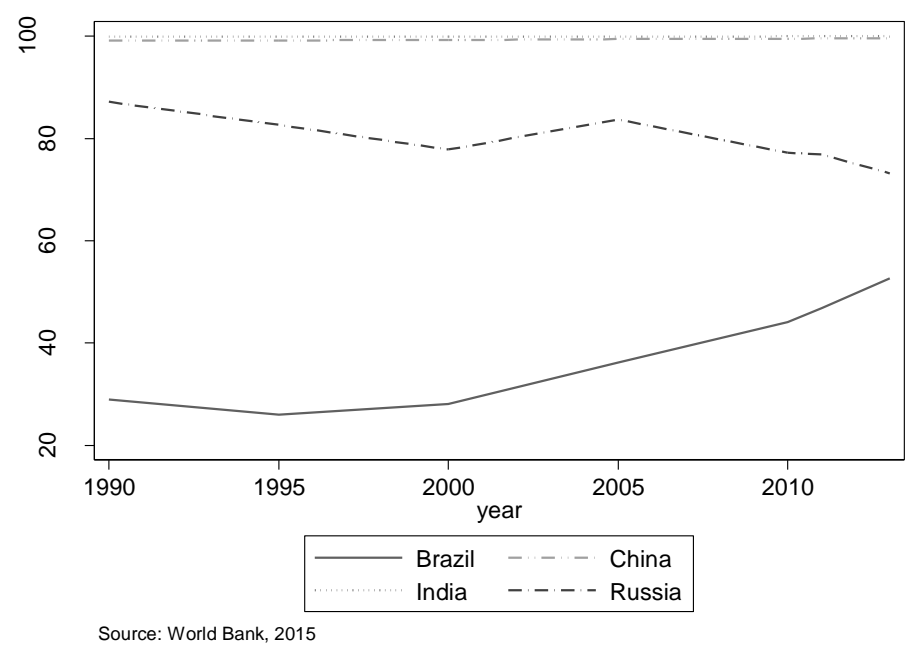

Figure 5. Population exposed to levels exceeding WHO guideline value of PM2.5 air pollution (\% of total) for BRICs from 1995-2013

The trade pattern that is observed today renders the following research question: why does the developing country that already suffers from its inferior health service wind up with specializing in the production of pollution-intensive goods and exporting to the developed country? Is this international division of labor efficient and sustainable?

This paper attempts to answer some of the above questions by exploring the sustainability of the resulting trade pattern in the presence of rising local pollution. This paper mainly focuses on harmful damage to health from local air pollutants such as PM2.5 because more than half of population in many developing countries, including China, is exposed to air pollution levels that exceed WHO guideline. Apart from the global pollution, which can cause global warming, developing countries suffer from hazardous local pollutants and may not be able to continue the expansion of dirty-good production. 
The paper introduces dual aspects of health capital to examine harmful effects of pollution. Being unhealthy depresses the ability to work productively and/or the ability and incentives to invest in human capital (Bleakly, 2010). However, health can also create welfare on its own, and healthy life does not necessarily mean materially rich life. These dual effects are modeled in the theoretical analysis to explain the rising social cost of pollution in developing countries (Note 8), and to draw implications for environmental cooperation to mitigate ever-worsening environmental degradation in developing countries.

The remainder of this paper is structured as follows: in section 2, the paper presents a brief review of the literature concerning environmental effects of international trade. In section 3.1, the paper presents the basic $A k$ model of endogenous growth with health capital. In section 3.2, the paper shows the model's implications on the pattern of trade between the developed country and the developing country. Concluding remarks follow in section 4.

\section{Environmental Effects of International Trade}

Environmental effects of international trade have been studied extensively in the literature. In particular, the search for the existence of so-called Pollution Haven Effect where pollution intensive industries flourish more in the countries with lax environmental standards has been one of the most debated topics in the literature. Some economists find that reduced trade barriers enable polluting producers to outsource their production activities to areas with lax environmental regulation (i.e., He, 2006; Copeland \& Taylor, 2004; Greenstone, 2002; Becker \& Henderson, 2000). However, the empirical evidence is not strong enough to support pollution haven hypothesis (i.e., Raspiller \& Riedinger, 2008; Eskeland \& Harrison, 1997; Birdsall \& Wheeler, 1993).

Despite the heated debate, the Pollution Haven Hypothesis has not provided persuasive insights into persistency of the current trade pattern between developing and developed countries other than the difference in environmental regulations. Greenstone and Jack (2015) have recently argued that developing and developed countries may have different marginal value on health improvement, and therefore, it creates the gap of pollution-reducing efforts between the two countries. An important research question remains on how income-induced differences in environmental standards between developing countries and advanced developed countries can have a long-lasting impact on the pattern of trade degrading the environment in a persistent manner along the growth path of developing countries. This issue becomes more challenging when the environmental standard of developing countries becomes more stringent over time. In fact, a number of studies find environmental standards should be changing with economic growth due to the negative effect on health from pollution (Note 5). In addition, many recent empirical studies have shown that the valuation of environmental quality increases as income level grows beyond a certain stage (i.e., Jalil \& Feridun, 2011; Hamit-Haggar, 2012; Cho et al., 2014).

The evidence that developing countries are valuing their marginal improvement on health capital can be seen from continuously increasing life expectancy and health expenditure of developing countries. As in Figure 6, the life expectancy at birth for the number of developing countries such as Brazil, India, Russia and China (BRICs) from 1960 has been increasing over time which implies that the economic value of life increases as their economies grow continuously.

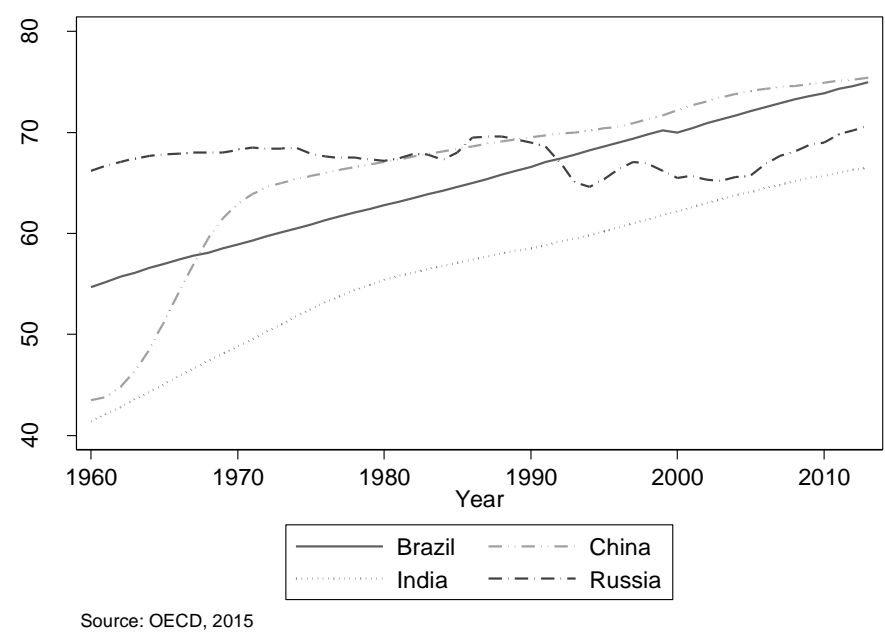

Figure 6. Life expectancy at birth for BRICs from 1960-2013 
Also, Figure 7 shows that the budget share of health expenditure of these four developing countries has been increasing monotonically over time. It shows that the governments of these newly industrializing countries are responding to rising social demand for healthier life. Greenstone and Jack (2015) have also pointed out that marginal costs of upgrading environmental quality are likely to be higher in developing countries. Over the past few decades, many developed countries and some developing countries have been actively involved in the innovation of so-called green technology (Note 6) to save energy and save the environment for future generations. As Figure 8 below illustrates, however, the technology gap of selected environmentally friendly technologies between OECD countries and BRICs still remains large (Note 7). The technology gap plays an important role in the trade pattern in the presence of rising environmental standard in developing countries. The previous literature and related empirical evidence suggest a need to examine causes of environmental degradation in an open developing economy by studying the pattern of trade between the developed country and the developing country and exploring the possibility of sustainable growth in an open economy.

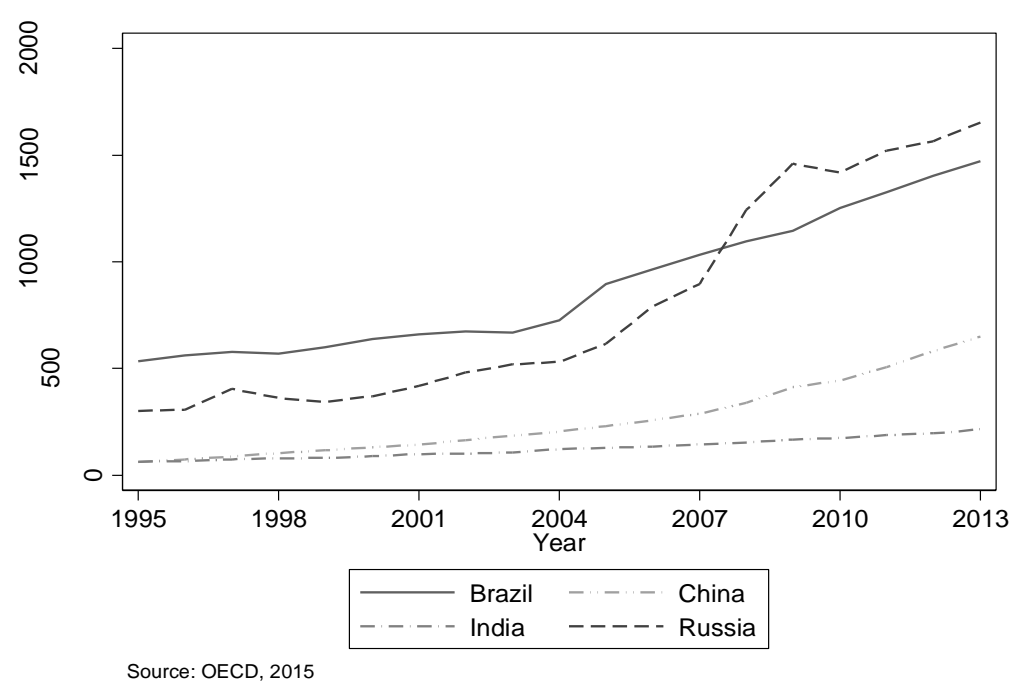

Figure 7. Per capita health expense for BRICs from 1995 - 2013

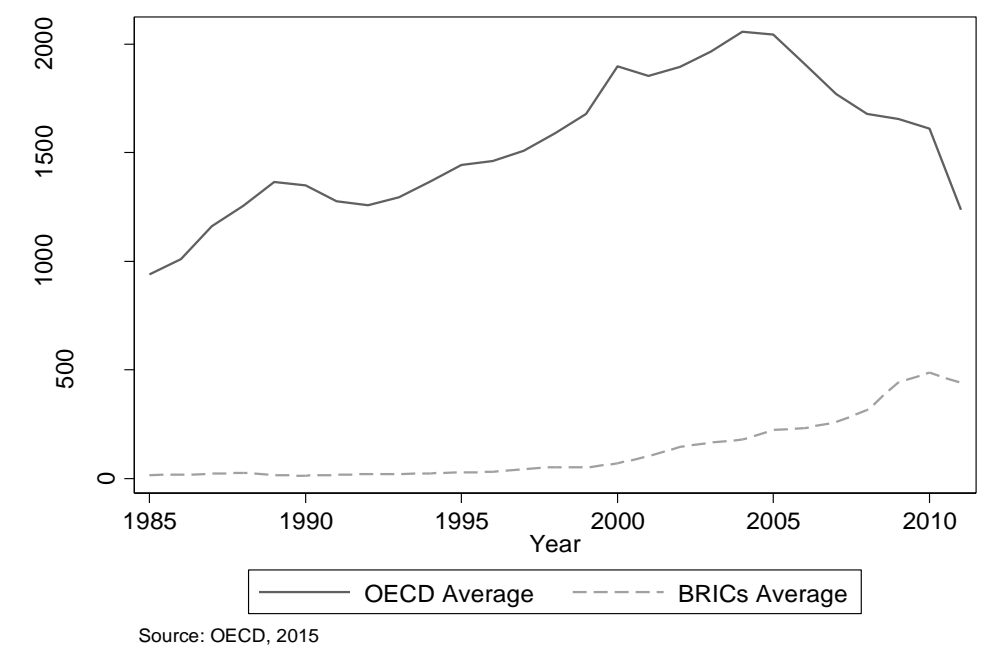

Figure 8. Selected environmentally friendly technologies invented from 1990-2011 for OECD countries and BRICs

This paper provides a framework to argue that as long as both developed and developing economies are productive enough to grow positively and regulate pollution emissions optimally over time, the developing 
country is bound to specialize in producing the pollution-intensive goods in a growing economy if there exists a sufficiently great technology gap in the production of environmentally friendly goods between the developed country and the developing country. As the developing economy grows over time, the marginal social cost of environmental damage to health increases, and the current trade pattern may no longer be sustainable.

\section{The Basic Model of Analysis}

\subsection{Economic Growth of a Small Open Economy}

We consider a model of endogenous growth of the representative small open economy with optimal environmental regulation. We assume that there are two kinds of goods: clean goods and dirty goods. The pollution is produced as a byproduct of the dirty good. The pollution hurts consumers' health and decreases welfare directly. It also induces consumers to spend more on medical care and reduces disposable income for consumption of dirty goods and for saving to invest in productive capital. The producer of the dirty good has to pay the pollution tax when the home government regulates pollution (Note 9).

Let $k$ denote the capital input available at time $t$ (Note 10). It is momentarily distributed between clean-good industry and dirty-good industry. Let $k_{d}$ denote the amount of capital input employed in the dirty-good sector. The pollution from the dirty sector is represented as the amount of emission flow per unit of production and is denoted as $x$. Following Cropper and Oates (1992), Lopez (1994) and Copeland and Taylor (2004), we regard pollution as a factor of production the price of which is optimally regulated by an environmental tax. Let $y_{d}=f\left(k_{d}, x\right)$ denote the production function of the dirty good; $f\left(k_{d}, x\right)$ is assumed to be increasing, strictly concave and linearly homogeneous in both variables.

The clean good is assumed to be produced using only the clean input that includes human capital and knowledge-based capital (Note 11). The technology is defined as follows,

$$
y_{c}=A\left(k-k_{d}\right)
$$

where we assume that the gross return to capital in the clean sector is a given as constant, $A$ over time.

The clean good is used both as consumption goods and as investment goods. Examples of the clean consumption good include medical and educational services and organic food, among others. We assume that the investment goods consist only of clean goods (Note 12).

Following Grossman (1972), we assume that the utility maximizing agent consumes the dirty consumption goods $\left(c_{d}\right)$ and the stream of health status $(h)$ at any given point in time in a complementary way. The stream of health status is derived from health capital $(H)$, which is assumed to have following characteristics:

(1) $H$ is inherited at the time of birth (Almond \& Mazumder, 2011); and

(2) $H$ depreciates by the environmental status (i.e., the level of pollution emissions), and the depreciation level can be reduced by the consumption of the clean goods (i.e., medical services) at any given time (Pautrel, 2012).

The utility can be expressed as a quasi-concave and increasing function $U\left(c_{d}, h\right)$ of $c_{d}$ and $h$. For analytical convenience, we assume that the stream of health status is a linear function of health capital so that

$$
h(t)=a H(t)
$$

where we normalize the constant $a$ to 1 . Let $C_{h}$ denote the consumer's expenditure on the clean good. Then the health capital over time is given as:

$$
\dot{H}=\beta H-\delta\left(x, c_{h}\right),
$$

where $\beta$ is the health renewal parameter that is determined by the natural environment and the state of medical science and $\delta$ is the health capital damage function (Note 13). The damage from pollution emissions includes negative direct effects on physical health (i.e., PM2.5). The indirect effects of pollution on the ability to conduct economic activities is accounted for later in this paper by the corresponding reduction in accumulation of human capital when the consumer spends more on clean goods (i.e., medical expenditure) to restore health capital.

Regarding the direct damage on physical health, we have the following assumption.

Assumption 1: The marginal damage of pollution to health capital is always positive, increasing in pollution 
level and decreasing in the consumption expenditure on clean goods. The pollution damage is decreasing in consumption of clean goods.

Assumption 1 implies that $\delta_{1}\left(x, c_{h}\right)>0, \delta_{2}\left(x, c_{h}\right)<0$ and $\delta_{11}\left(x, c_{h}\right) \geq 0, \delta_{22}\left(x, c_{h}\right) \geq 0$ with $\delta_{12}\left(x, c_{h}\right)=\delta_{21}\left(x, c_{h}\right)<0$ where the subscripts denote the first differentiation of $\delta$ with respect to first or second arguments (Note 14).

Throughout the paper, we are mainly concerned about the damage from domestic pollution and disregard damage from global pollution, such as carbon dioxide. As we explained in the introductory section, China's local pollution level has increased beyond the WHO safety guideline, threatening the urban health. This paper examines the sustainability of the current trade structure by considering environmental degradation of developing countries from local pollutants.

The competitive economy with government is described as follows. The consumer holds the capital stock $k$ of firm and health capital, $H$. Let $p$ denote the relative price of the dirty good. The clean good is used as the numeraire good. The government imposes environment tax $\tau$ to regulate the pollution at the optimal level.

Assuming that the government reimburses tax receipt in a lump-sum way and assuming the clean sector, we note that the income of the consumer who owns the capital stock of firms in both clean and dirty sectors consists of revenue from clean-good and dirty-good industry,

$$
A\left(k-k_{d}\right)+p f\left(k_{d}, x\right) .
$$

The consumption expenditure is defined as $E=c_{h}+p c_{d}$. Then the gross investment carried by the clean good,

$I$, is defined as income net expenditure,

$$
I=A\left(k-k_{d}\right)+p f\left(k_{d}, x\right)-E
$$

and $\dot{k}=\frac{d k}{d t}=I-E-\phi k$ where $\phi>0$ is the capital depreciation parameter (Note 15).

We note that the net import of the dirty good, $I M_{d}$, is defined as $I M_{d}=p\left(c_{d}-f\left(k_{d}, x\right)\right)$, and the net import of the clean good, $I M_{c}$, is defined as $I M_{c}=c_{h}-A\left(k-k_{d}\right)$. Then the gross investment of the economy $I$ can be expressed as $I=-\left(I M_{c}+I M_{d}\right)$ so that the trade balance equals net investment.

To examine environmental degradation in a growing economy, we maintain the following assumption throughout the paper (Note 16).

Assumption 2: The economy is productive enough so that the net return to capital is greater than the marginal opportunity cost of capital. In other words, $A>r+\phi$ where $r$ is a fixed pure time discount rate.

Assumption 2 is needed to sustain the growth process of the model economy.

We describe the consumer's problem as follows:

$$
\operatorname{MAX} \int_{0}^{\infty} U\left(c_{d}, h\right) e^{-r t} d t
$$

subject to

$$
\begin{gathered}
\text { (i) } \dot{k}=A\left(k-k_{d}\right)+p f\left(k_{d}, x\right)-p c_{d}-c_{h}-\phi k \\
\text { (ii) } \dot{H}=\beta H-\delta\left(x, c_{h}\right) \text {, and } \\
\text { (iii) } H(0)=H_{0}, \quad k(0)=k_{0}
\end{gathered}
$$

For expositional convenience, we can replace the health capital by the flow variable, the stream of health asset $h(t)$ by the assumption on the normalization of the parameter $a$. The current value Hamiltonian $\tilde{\mathrm{H}}$ can be defined as follows:

$$
\tilde{\mathrm{H}}=U\left(c_{d}, h\right)+\lambda\left[A\left(k-k_{d}\right)+p f\left(k_{d}, x\right)-p c_{d}-c_{h}-\phi k\right]+\mu\left[\beta H-\delta\left(x, c_{h}\right)\right]
$$


It follows that we have the following necessary conditions:

$$
\begin{gathered}
U_{1}\left(c_{d}, h\right)=p \lambda, \\
\lambda=-\mu \delta_{2}\left(x, c_{h}\right), \\
\dot{\lambda}=\lambda(r+\phi-A), \\
\dot{\mu}=\mu(r-\beta)-U_{2}\left(c_{d}, h\right), \\
\dot{k}=A\left(k-k_{d}\right)+p f\left(k_{d}, x\right)-p c_{d}-c_{h}-\phi k, \text { and } \\
\dot{H}=\beta H-\delta\left(x, c_{h}\right) .
\end{gathered}
$$

Because the firm maximizes profits, we also have

$$
\begin{gathered}
p f_{1}\left(k_{d}, x\right)=A, \text { and } \\
\lambda p f_{2}\left(k_{d}, x\right)=\mu \delta_{1}\left(x, c_{h}\right) .
\end{gathered}
$$

Finally, the transverality conditions hold:

$$
\lim _{t \rightarrow \infty} \lambda(t) k(t) e^{-r t}=0, \text { and } \lim _{t \rightarrow \infty} \mu(t) H(t) e^{-r t}=0 .
$$

Equation (7) implies that for the small open economy, the factor ratio $k_{d} / x$ is fixed over time as long as the world price of the dirty good remains constant. It implies that for a small open economy, the marginal return of using pollution input remains constant regardless of the pollution level. Furthermore, because $y=x f\left(\frac{k_{d}}{x}, 1\right)$, the growth rate of the domestic output of the dirty industry is the same as the growth rate of pollution emission.

Equation (8) states that given the maximizing behavior of the consumer and the firm, the government decides on the pollution $\operatorname{tax}(\tau)$ to maximize the welfare of consumers. In other words, the government regulates the pollution in such a way that the social value of an increase in profits is equal to the social cost of health capital. That is, $\tau=\left(\frac{\mu}{\lambda}\right) \delta_{1}\left(x, c_{h}\right)$.

We note that from Equation (2) that

$$
\hat{\lambda}=\hat{\mu}+\hat{\delta}_{2}=\hat{\mu}+\varepsilon_{21} \hat{x}+\varepsilon_{22} \hat{c}_{h}
$$

where $\varepsilon_{21}=\frac{\delta_{21}\left(x, c_{h}\right)}{\delta_{2}\left(x, c_{h}\right)} x$ and $\varepsilon_{22}=\frac{\delta_{22}\left(x, c_{h}\right)}{\delta_{2}\left(x, c_{h}\right)} c_{h}$.

Because the production function is linearly homogenous, we have that

$$
\lambda p f_{2}\left(\frac{k_{d}}{x}, 1\right)=\mu \delta_{1}\left(x, c_{h}\right)
$$

Noting that $\frac{k_{d}}{x}$ is fixed over time as long as the price $p$ and technology parameter $A$ are fixed and differentiating (11) with respect to time, we have

$$
\hat{\lambda}=\hat{\mu}+\eta_{11} \hat{x}+\eta_{12} \hat{c}_{h}
$$

where $\eta_{11}=\frac{\delta_{11}\left(x, c_{h}\right)}{\delta_{1}\left(x, c_{h}\right)} x$ and $\eta_{12}=\frac{\delta_{12}\left(x, c_{h}\right)}{\delta_{1}\left(x, c_{h}\right)} c_{h}$.

It follows from Equations (10) and (12) that 


$$
\hat{x}=\frac{\left(\varepsilon_{22}-\eta_{12}\right)}{\left(\eta_{11}-\varepsilon_{21}\right)} \hat{c}_{h}
$$

Furthermore, from Equation (3), we have

$$
\hat{\lambda}=(r+\phi-A)
$$

which implies that the shadow price of physical capital decreases over time if $A$ is sufficiently large. That is, if $A>r+\phi$, the growth rate of the economy becomes positive. More concretely, we have from the Equation (1) that

$$
\hat{\lambda}=\frac{U_{11}\left(c_{d}, h\right)}{U_{1}\left(c_{d}, h\right)} c_{d} \hat{c}_{d}+\frac{U_{12}\left(c_{d}, h\right)}{U_{1}\left(c_{d}, h\right)} h \hat{h}
$$

Let $e\left(c_{d}\right)=-\left(\frac{U_{11}\left(c_{d}, h\right)}{U_{1}\left(c_{d}, h\right)} c_{d}\right)$ denote the elasticity of marginal utility of the dirty good with respect to consumption of the dirty good. Let $e(h)\left(=\frac{U_{12}\left(c_{d}, h\right)}{U_{1}\left(c_{d}, h\right)} h\right)$ denote the elasticity of marginal utility of the dirty good with respect to the flow of health service. If $U_{12}\left(c_{d}, h\right)>0$, we have that $e(h)>0$. We can rewrite Equation (14) using $e(h)$ as:

$$
A-r-\phi=e(c) \hat{c}_{d}-e(h) \hat{h} .
$$

For example, if we assume the Cobb-Douglas utility function $U\left(c_{d}, h\right)=c_{d}{ }^{\alpha} h^{1-\alpha}$, we have from Equation (1) that $\alpha\left(\frac{h}{c_{d}}\right)^{1-\alpha}=p \lambda$. It follows that $\hat{\lambda}=(1-\alpha)\left(\hat{h}-\hat{c}_{d}\right)=(r+\phi-A)<0$ and $\hat{c}_{d}=\hat{h}+\frac{A-\phi-r}{1-\alpha}$ so that $c_{d} / h$ increases over time in a growing economy.

From Equation (16) the following proposition follows.

Proposition 1. Assume that the marginal utility of the dirty consumption goods increases as the consumer becomes healthier so that $U_{12}\left(c_{d}, h\right)>0$. If the economy is productive enough $(A>r+\phi)$, the consumption of the dirty good grows positively as long as health capital grows over time.

Proof. In the text.

\subsection{Implications for the Pattern of Trade between the Developed Country and the Developing Country}

To examine the possibility of equilibrium between the developed and developing countries, let us assume that many small developing and developed open economies act as price takers in the world market. From the analysis of necessary conditions, we find that the growth rate of consumption of dirty goods is always positive in both developing and developed countries as long as the productivity of the clean sector is sufficiently great and health capital grows over time. Because the global supply and demand for the dirty good must be balanced, $\hat{x}$ cannot be negative in both developed and developing countries. If $f\left(k_{d}, x\right)>c_{d}$ in the developing country, the excess is exported to the developed country to finance the import of the clean goods.

Let $A^{i}$ for $i=S, N$ denote the return to capital in the developing and the developed country, respectively. Let us assume that $A^{N}>A^{S}$. Assume also for expositional convenience that the production function, $f\left(k_{d}, x\right)$, of the dirty good is the same for both countries. Then given the world price of the dirty good, $p$, the equilibrium factor ratio between capital and pollution input in the dirty industry is derived from the Equation (7): $p f_{1}\left(k_{d}, x\right)=A$ or $\quad \frac{k_{d}}{x}=R(p, A)$ where $\frac{\partial R}{\partial p}>0$.

Let $x^{N}$ and $x^{S}$ denote the pollution emission in the developed and developing country, respectively. Let $c_{d}{ }^{N}$ 
and $c_{d}{ }^{S}$ denote the consumption of the dirty good in each country. Then at market equilibrium,

$$
F\left(R\left(p, A^{N}\right), 1\right) x^{N}+F\left(R\left(p, A^{S}\right), 1\right) x^{S}=c_{d}^{N}+c_{d}{ }^{S}=c_{d}{ }^{W}
$$

where $c_{d}{ }^{W}$ denote the aggregate world consumption of the dirty good. Under Assumption 2 for a growing economy, both $c_{d}{ }^{N}$ and $c_{d}{ }^{S}$ are increasing in each country. Because $A^{N}>A^{S}$, we have for any given world price of the dirty good $p, R\left(p, A^{N}\right)<R\left(p, A^{S}\right)$, and the developing country produces more of the dirty good than the developed country. If Equation (17) holds at any point in time, then we cannot have $\dot{x}^{N}<0$ and $\dot{x}^{S}<0$ simultaneously over time.

We summarize the above analysis in the following corollary to Proposition 1.

Corollary 1. Assume that both developing and developed countries are productive enough so that $A^{i}-\phi-r>0, i=S, N$. Then the growth rate of the dirty sector in at least one of the developed and developing countries should be positive provided that the health capital in both countries increases over time.

Corollary 1 states that pollution emissions cannot decline in every country when each country grows over time. In fact, this proposition is consistent with the empirical evidence in the introductory section that the pollution emissions increase in the growing developing country.

\subsection{Feasibility of Sustainable Growth}

In this section, we examine the feasibility of sustainable growth in developing open economy with the trade. From Equation (4), we have

$$
\hat{\mu}=(r-\beta)-\left(\frac{1}{\mu}\right) U_{2}\left(c_{d}, h\right) .
$$

Inserting (18) into (12) and using (14), we have

$$
\hat{x}=\left(\frac{1}{\theta}\right)\left[(\beta+\phi-A)+\frac{U_{2}\left(c_{d}, h\right)}{\mu}\right]
$$

where $\theta=\eta_{11}+\eta_{12}\left(\frac{\eta_{11}-\varepsilon_{21}}{\varepsilon_{22}-\eta_{12}}\right)$.

Applying Equations (1) and (11) and homogeneity property of production function, Equation (19) can be written as

$$
\left(\frac{U_{2}\left(c_{d}, h\right)}{U_{1}\left(c_{d}, h\right)}\right) \frac{\delta_{1}\left(x, c_{h}\right)}{f_{2}\left(\frac{k_{d}}{x}\right)}=\theta \hat{x}-(\beta-(\mathrm{A}-\phi))
$$

The left-hand side of Equation (20) is a ratio between the marginal damage of pollution measured in terms of dirty goods (which is a product of the marginal rate of substitution of health for the dirty good and the marginal damage of pollution to health) to the marginal product of pollution in the dirty sector, which is fixed by exogenously given world prices. The marginal damage of pollution measured in terms of dirty goods is in fact the marginal social cost of pollution. Equation (20) expresses the marginal social damage of pollution in terms of the growth rate of the dirty sector (or pollution), health renewal rate and the return to capital in the clean sector, all of which are empirically observable.

To draw implications for the feasibility of growth path, let us assume for simplicity that $\delta_{12}=0$ so that $\theta>0$ under Assumption 1. Equation (20) states that the marginal social cost of pollution increases as the growth rate of the dirty sector (or pollution) increases. In other words, if a developing country grows by increasing specialization in a pollution-intensive industry, the social cost of pollution increases. In fact, when the economy grows, $c_{d} / h$ increases (Proposition 1), and if the utility function of the consumer is homothetic, the marginal rate of substitution of health for the dirty good is an increasing function of $c_{d} / h$. Furthermore, under 
Assumption 1, pollution damage is an increasing convex function of pollution so that the marginal damage to health increases in the emission level.

Equation (20) also implies that the effect of the growth of the dirty sector on the social cost of pollution is lessened if the health renewal rate increases. If the value of health renewal parameter is sufficiently greater than the net return to capital, pollution growth may have little effect on the marginal social costs of pollution. Otherwise, the growth of the dirty sector becomes increasingly socially expensive and cannot be sustained in the long run.

\section{Conclusion}

The paper examines the possible pattern of trade between the developed and developing countries when both economies grow over time. The paper assumes that the developed country has superior technology in the production of the clean good while both economies have the same technology in the production of the dirty good. The paper also assumes that both economies adopt optimal regulation of pollution in a model of endogenous growth in an open economy. The paper shows that the growing developing country engages more in the production of the dirty good where it has a comparative advantage to afford increasing import of the clean good. As a result, the marginal social cost of pollution in the growing developing country increases in proportion to the growth rate of the dirty sector.

Empirical observation suggests that the technology gap between developed and developing countries in the clean sector remains sufficiently great to sustain the shift of the dirty industry to developing countries. As a result, the marginal social cost of pollution in the growing developing country increases in proportion to the growth rate of the dirty sector. On the other hand, the recent data illustrate that the social preferences for improving health in the developing country are increasing rapidly. Once the developing country adopts optimal environmental regulation, the tax burden in the dirty sector will decrease the scale of production of the dirty good in developing countries, eventually slowing down the growth of the world economy. The challenging problems that the developing countries face to reduce the environmental burden of the dirty industry by structural adjustment illustrate the difficulty associated with sustainability of the current trade structure between developing and developed countries.

This paper suggests that there is a great scope for global environmental cooperation to make the current trade structure more sustainable by upgrading environmental technology in developing countries. Although the barrier to the commercial transfer of environmental technology to developing countries has been reduced considerably, there is a compelling need for an early resolution of debates on the broad institutional framework that covers public good aspects of environmental technology between developed and developing countries.

The policy implications of a broader framework are possible only if the effects of global pollution such as carbon dioxide are examined. Although the sources of both local and global pollution are often the same, the free riding aspects of global pollution are harder to handle and are left for future research.

\section{References}

Ahmad, N., \& Wyckoff, A. (2003). Carbon dioxide emissions embodied in international trade of goods. DSTI/DOC(2003)15; Organisation for Economic Co-operation and Development (OECD): Paris, 2003. Retrieved from http://www.oecd.org/sd-roundtable/papersandpublications/39376504.pdf

Almond, D., \& Mazumder, B. (2011). Health capital and the prenatal environment: The effect of Ramadan observance during pregnancy. American Economic Journal: Applied Economics, 56-85. http://www.aeaweb.org/articles.php?doi=10.1257/app.3.4.56

Becker, R., \& Henderson, V. (2000). Effects of air quality regulations on polluting industries. Journal of Political Economy, 108(2), 379-421. http://dx.doi.org/10.1086/262123

Birdsall, N., \& Wheeler, D. (1993). Trade policy and industrial pollution in Latin America: Where are the pollution havens? The Journal of Environment \& Development, 2(1), 137-149. http://dx.doi.org/10.1177/107049659300200107

Bleakley, H. (2010). Health, human capital, and development. Annual Review of Economics, 2, 283. http://dx.doi.org/10.1146/annurev.economics.102308.124436

Cho, C. H., Chu, Y. P., \& Yang, H. Y. (2014). An environment Kuznets Curve for GHG emissions: A Panel Cointegration Analysis. Energy Sources, Part B: Economics, Planning, and Policy, 9(2), 120-129. http://dx.doi.org/10.1080/15567241003773192

Copeland, B. R., \& Taylor, M. S. (2004). Trade, Growth, and the Environment. Journal of Economic Literature, 


\section{2, 7-71. http://dx.doi.org/10.1257/002205104773558047}

Cropper, M. L., \& Oates, W. E. (1992). Environmental economics: A survey. Journal of Economic Literature, 30(2), 675-740.

Druckman, A., Bradley, P., Papathanasopoulou, E., \& Jackson, T. (2008). Measuring progress towards carbon $\begin{array}{llll}\text { reduction in the UK. Ecological Economics, 66(4), 594-604. } & \text {. }\end{array}$ http://dx.doi.org/10.1016/j.ecolecon.2007.10.020

Eskeland, G. S., \& Harrison, A. E. (2003). Moving to greener pastures? Multinationals and the pollution haven $\begin{array}{llll}\text { hypothesis. Journal of development economics, } & 70(1), & 1-23 \text {. }\end{array}$ http://dx.doi.org/10.1016/S0304-3878(02)00084-6

Greenstone, M. (2002). The Impacts of Environmental Regulations on Industrial Activity: Evidence from the 1970 and 1977 Clean Air Act Amendments and the Census of Manufactures. Journal of Political Economy, 110(6), 1175-1219. http://dx.doi.org/10.1086/342808

Greenstone, M., \& Jack, B. K. (2015). Envirodevonomics: A Research Agenda for an Emerging Field. Journal of Economic Literature, 53(1), 5-42. http://dx.doi.org/10.1257/jel.53.1.5

Grossman, M. (1972). On the concept of health capital and the demand for health. Journal of Political economy, 80(2), 223-255. http://dx.doi.org/10.1086/259880

Gutierrez, M. J. (2008). Dynamic inefficiency in an overlapping generation economy with pollution and health $\begin{array}{lllll}\text { costs. Journal of Public Economic Theory, 10(4), 563-594. } & \text {. }\end{array}$ http://dx.doi.org/10.1111/j.1467-9779.2008.00377.x

Hamit-Haggar, M. (2012). Greenhouse gas emissions, energy consumption and economic growth: A panel cointegration analysis from Canadian industrial sector perspective. Energy Economics, 34(1), 358-364. http://dx.doi.org/10.1016/j.eneco.2011.06.005

He, J. (2006). Pollution haven hypothesis and environmental impacts of foreign direct investment: The case of industrial emission of sulfur dioxide (SO 2) in Chinese provinces. Ecological economics, 60(1), 228-245. http://dx.doi.org/10.1016/j.ecolecon.2005.12.008

Jalil, A., \& Feridun, M. (2011). The impact of growth, energy and financial development on the environment in China: A cointegration analysis. Energy Economics, 33(2), 284-291.

Levinson, A. (2010). Offshoring pollution: Is the United States increasingly importing polluting goods? Review of Environmental Economics and Policy, 4(1), 63-83. http://dx.doi.org/10.1093/reep/rep017

López, R. E., \& Yoon, S. W. (2014a). "Sustainable" Economic Growth: The Ominous Potency of Structural Change. International Review of Environmental and Resource Economics, 7(2), 179-203. http://dx.doi.org/10.1561/101.00000060

López, R. E., \& Yoon, S. W. (2014b). Pollution-income dynamics. Economics Letters, 124(3), 504-507. http://dx.doi.org/10.1016/j.econlet.2014.07.024

OECD. (2015). OECD.Stat, (database). http://dx.doi.org/10.1787/data-00285-en

Pautrel, X. (2007). Pollution, Health and Life Expectancy: How Environmental Policy Can Promote Growth. No 2007. 96, Working Papers, Fondazione Eni Enrico Mattei.

Pautrel, X. (2012). Pollution, Private Investment in Healthcare, and Environmental Policy. The Scandinavian Journal of Economics, 114(2), 334-357. http://dx.doi.org/10.1111/j.1467-9442.2012.01696.x

Raspiller, S., \& Riedinger, N. (2008). Do Environmental Regulations Influence the Location Behavior of French Firms? Land Economics, 84(3), 382-395. http://dx.doi.org/ 10.3368/le.84.3.382

Tanaka, S. (2015). Environmental regulations on air pollution in China and their impact on infant mortality. Journal of Health Economics, 42, 90-103. Environmental regulations on air pollution in China and their impact on infant mortality http://dx.doi.org/10.1016/j.jhealeco.2015.02.004

WHO. (2013). Health effects of particulate matter. The World Health Organization, pp. 1-20.

\section{Notes}

Note 1. Service includes business sector services such as telecommunication and financial intermediation, and community and personal services, such as education and health services (OECD, 2015). 
Note 2. See Copeland and Taylor (2004) for the survey of the literature on this topic.

Note 3. Study has shown that the daily mortality increases by $0.2-0.6 \%$ per $10 \mu \mathrm{g} / \mathrm{m} 3$ of PM10 and by $6-13 \%$ per $10 \mu \mathrm{g} / \mathrm{m} 3$ of PM2.5 (WHO, 2013).

Note 4. See http://www3.epa.gov/pm/health.html for more information.

Note 5. Gutierrez (2008) analyzed the cumulative effect of pollution on health and argues that households carry the burden of health costs that results from environmental degradation and that the economy will become dynamically inefficient as pollution levels increase. Pautrel (2007) considers a dynamic general equilibrium model with an overlapping framework where the pollution has negative impact on health, such as reduction of life expectancy. He explains that greener preference or environmental regulation is likely to promote long-term growth because a better health status makes workers more productive.

Note 6. The green technology includes bio, nano, ICT, pharmaceuticals, climate change mitigation technologies related to buildings, capture, storage, sequestration or disposal of greenhouse gases, environmental management, climate change mitigation technologies related to transportation and water-related adaptation technologies. See OECD (2015).

Note 7. Selected environmentally friendly technologies for the comparison in Figure 8 are: Climate change mitigation technologies related to buildings; Climate change mitigation technologies related to energy generation, transmission or distribution; Capture, storage, sequestration or disposal of greenhouse gases; Environmental management; Climate change mitigation technologies related to transportation; Water-related adaptation technologies. See OECD (2015).

Note 8 . In many countries, a large number of old population members do not work even though they spend more on health than do younger people.

Note 9. We assume that the effect of pollution is confined to the country where it originates.

Note 10. The input includes physical capital as well as human capital. Hereafter we refer to this input as a composite input.

Note 11. It includes computerized information (software and databases), innovative property (patents, copyrights, designs and trademarks) and economic competencies (including brand equity, firm-specific human capital, networks of people and institutions, and organizational know-how that increases enterprise efficiency).

Note 12. One can model the economy where the investment good consists of dirty goods. In this case, however, the real return to capital in the dirty sector is likely to decrease over time if the government regulates environment in an optimal way. Then the dirty sector eventually shrinks over time, and sustainable development becomes infeasible.

Note 13. Note that the clean good enters the utility function by reducing the depreciation rate of health capital.

Note 14. We maintain subscript number $n$ of any function to denote the first differentiation of the function's nth arguments throughout the paper.

Note 15. We note that there exists indirect effect of pollution damage on accumulation of capital when the consumer increases expenditure on clean goods such as medical services to reduce pollution damage to health.

Note 16. See Lopez and Yoon (2014b) for further implications of this assumption.

\section{Copyrights}

Copyright for this article is retained by the author(s), with first publication rights granted to the journal.

This is an open-access article distributed under the terms and conditions of the Creative Commons Attribution license (http://creativecommons.org/licenses/by/3.0/). 